\title{
Status of Antioxidant Enzymes and Lipid Peroxidation in Type 2 Diabetes Mellitus with Micro Vascular Complications
}

\author{
Manjulata Kumawat ${ }^{1}$, Manju Bala Pahwa, ${ }^{*}$, , Veena Singh Gahlaut ${ }^{1}$ and Neelima Singh ${ }^{2}$ \\ ${ }^{I}$ Department of Biochemistry, Pt. BDS, University College of Medical Sciences, Rohtak-124001, India \\ ${ }^{2}$ Department of Biochemistry, G.R. Medical College, Gwalior, India
}

\begin{abstract}
In diabetic patients, persistence of hyperglycemia has been reported as a cause of increased production of oxygen free radicals. Hyperglycemia could induce oxidative stress and become the main factor for predisposing the complications in diabetes. The study is being aimed to find out the status of lipid peroxidation product i.e. malondialdehyde (MDA) and antioxidant enzymes (AOEs) such as glutathione peroxidase (GPx), glutathione reductase (GR), catalase (CAT), superoxide dismutase (SOD) and reduced glutathione (GSH) which might be helpful in risk assessment of various complications of diabetes mellitus.
\end{abstract}

The study included 300 subjects (50-70yrs) out of which 150 patients were non insulin dependent diabetes mellitus (NIDDM) with micro vascular complications and 150 age matched healthy controls. The status of fasting blood sugar (FBS), reduced glutathione (GSH), GPx, GR, CAT, SOD and MDA were determined.

Our results showed significant increase $(\mathrm{p}<0.001)$ in FBS, CAT and MDA while GSH, GPx, GR and SOD were found decreased significantly $(\mathrm{p}<0.001)$.

The data suggest that alteration in antioxidant status and MDA may help to predict the risk of various micro vascular complications of diabetes mellitus.

Keywords: Non insulin dependent diabetes mellitus, Antioxidant enzymes, Malondialdehyde, Micro vascular complications.

\section{INTRODUCTION}

Diabetes mellitus is a major health problem throughout the world. It is a group of metabolic disorders characterised by hyperglycemia and glycosuria with disturbances in carbohydrate, fat and protein metabolism resulting from either an absolute or relative deficiency of insulin secretion or action [1]. It is classified into Type 1 Insulin dependent diabetes mellitus (IDDM) which refers to a condition where there is chronic progressive beta cell destruction and Type 2 Non insulin dependent diabetes mellitus (NIDDM) is the most common type of diabetes. The disease is due to the decreased biological response to insulin, otherwise called insulin resistance, so there is relative insulin deficiency. In the early stages, the beta cells respond to the insulin resistance by secreting increased quantities of insulin and thus maintain blood sugar at normal levels. But gradually the beta cells begin to fail and the insulin levels decrease, resulting in rising levels of blood sugar. So it is a combination of insulin resistance and beta cell failure that causes Type 2 diabetes mellitus.

Recently it has been reported that auto oxidation of glucose due to persisting hyperglycemia in diabetes mellitus is major cause for generating oxidative stress [2]. Many factors are responsible for this like polyol pathway, prostanoid synthesis and protein glycation which disturbs the antioxidant

*Address correspondence to this author at the H. NO., 21/9J, Medical Enclave, PGIMS, Rohtak.-124001, India;

E-mail: manjupahwadoc1@yahoo.co.in defence system of the cell by increasing the functional activities of superoxide anion $\left(\mathrm{O}_{2}^{-}\right)$, the hydroxyl radical $\left(\mathrm{OH}^{-}\right)$ and hydrogen peroxide $\left(\mathrm{H}_{2} \mathrm{O}_{2}\right)$. There are reports that in diabetics the disturbed equilibrium between prooxidants and antioxidants alters the metabolic status of body leading to the development of micro vascular (retinopathy, nephropathy, neuropathy) complications [3]. Under normal conditions, free radicals are formed in minute quantities and are rapidly scavenged by natural cellular defense mechanisms comprising of enzymes like superoxide dismutase (SOD), glutathione peroxidase (GPx), glutathione reductase (GR), catalase (CAT) etc. An increased production of malondialdehyde (MDA), a marker for lipid peroxidation has been found in erythrocyte membrane of diabetic patients together with depressed erythrocyte content i.e. antioxidant enzymes (AOEs) and reduced glutathione (GSH) [4].

In view of the above considerations the present study was aimed to evaluate the degree of oxidative stress (OS) in Micro vascular complications of diabetes mellitus.

\section{MATERIALS AND METHODS}

The present study was carried out in the Department of Biochemistry, G.R. Medical College, Gwalior. All patients will be taken from medical wards/ ICU/OPD of JA group of hospital, Gwalior, under the supervision of medical officer and the written consent was also taken from patients before analysis of blood. All ethical norms were followed during study. The study included 300 subjects (50-70 years) out of which 150 patients were of NIDDM with Micro vascular complications. Type-2 DM patients with complications were 
diagnosed on the basis of history, physical examination, biochemical investigations and according to the biochemical criteria laid down by the National Diabetes Data Group (NDDG) of the National Institute of Health in 1980 / WHO criteria. Patients with acute \& chronic inflammatory conditions as well as smokers, alcoholics, and primary hypertensives were excluded from the study. Patients with multiple or associated complications were also excluded from the study All the diabetics were on hypoglycemic drugs. None of the subjects were on antioxidant supplementation or lipid lowering drugs. 150 age matched apparently healthy individuals with normal plasma glucose, normal vision and with no symptoms suggestive of Diabetes Mellitus were taken as control.

All subjects were undergone routine investigations like blood sugar, lipid profile, renal profile, urine examination. Fundus examination was to done for retinopathy. Cases of diabetic retinopathy were diagnosed by the ophthalmologist by

- Direct Ophthalmoscopy

- Binocular Indirect Ophthalmoscopy

- Slit lamp Examination

Cases of Diabetic Retinopathy include both types Proliferative \& Non Proliferative Diabetic Retinopathy.

These vascular complications are grouped as:

Group 1. With diabetic neuropathy $(\mathrm{N}=50)$

Group 2. With diabetic nephropathy $(\mathrm{N}=50)$

Group 3. With diabetic retinopathy $(\mathrm{N}=50)$

5-ml blood sample was collected in fasting condition for the analysis of various parameters:

1. Fasting Blood Sugar (FBS) was estimated by method of GOD-POD Trinder [5].

2. Reduced glutathione (GSH) was estimated by method of Beutler et al. [6].

3. Glutathione peroxidase (GPx) was estimated by method of Hafeman et al. [7].

4. Glutathione reductase (GR) ) was estimated by method of Horn [8].

5. Catalase (CAT) was estimated by method of Sinha [9].

6. Superoxide dismutase (SOD) was estimated by method of Mishra et al. [10].

7. Plasma malondialdehyde (MDA) was estimated by method of Jean et al. [11].

The statistical analysis was done by ANOVA test.

\section{RESULTS AND DISCUSSION}

In Type 2 diabetic subjects suffering from Micro vascular complications (Figs. 1-7, Table 1) with increasing age, the activity of antioxidant enzymes (AOEs) was found to be decreased significantly $[12,13]$. We observed a significant decrease in reduced Glutathione (GSH), Glutathione peroxidase (GPx), Glutathione reductase (GR) and Superoxide

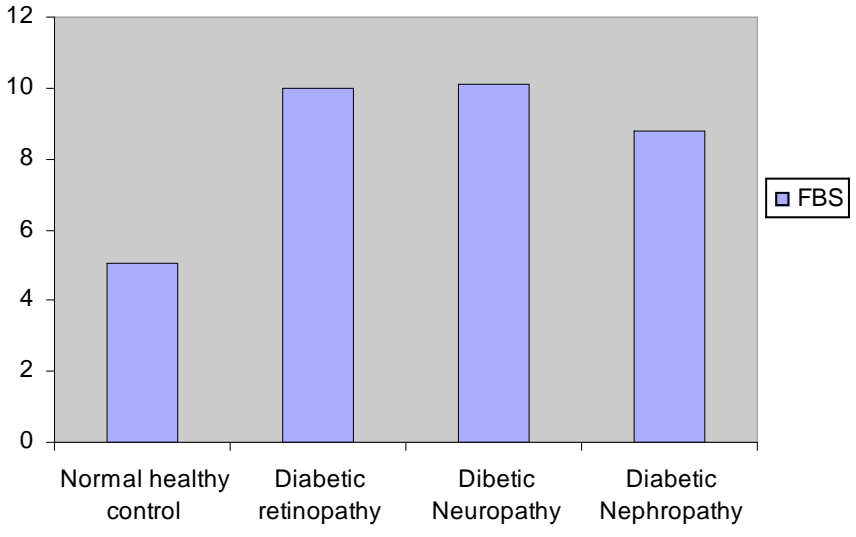

Fig. (1). Comparision of Fastng Blood sugar in cases and control group.

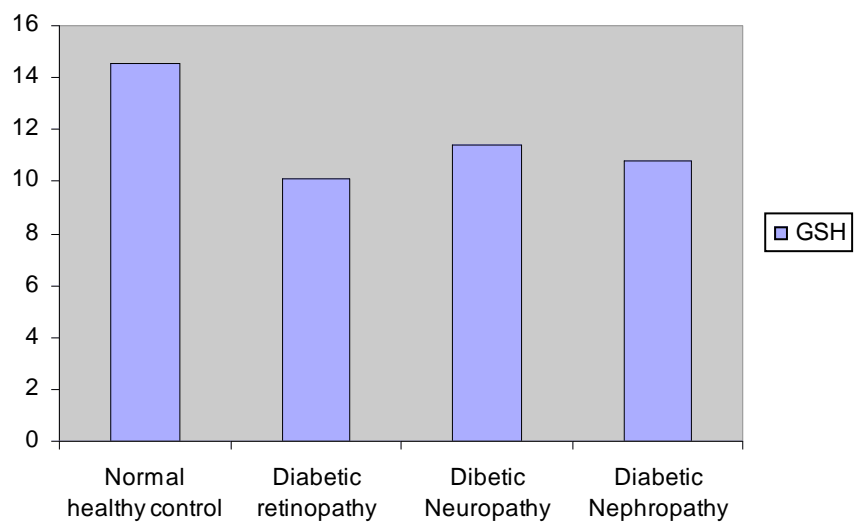

Fig. (2). Comparision of Reduced Glutathione in cases and control group.

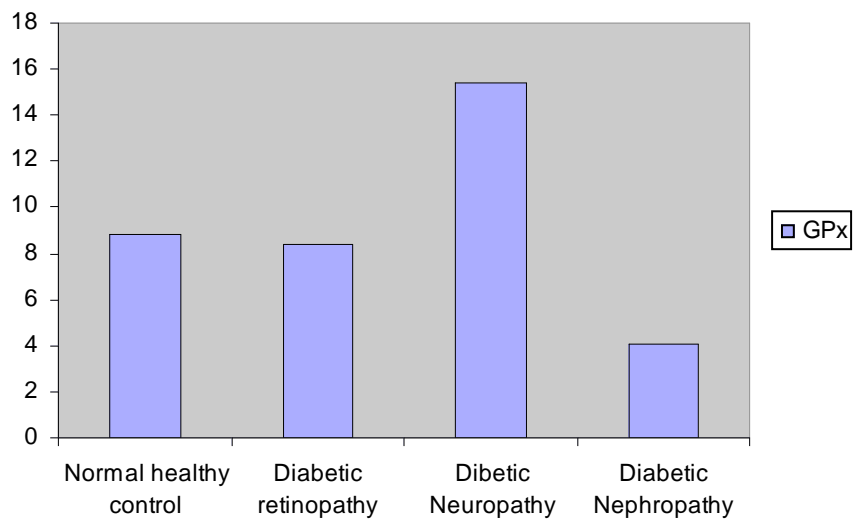

Fig. (3). Comparision of Glutathione Peroxidase in cases and control group.

dismutase (SOD) with the exception, an increase in activity of Catalases as compared to the control subjects. However the fasting blood sugar (FBS) and malondialdehyde (MDA) levels were found significantly increased. In our study we have used erythrocytes as a model to study oxidative stress (OS). It is a target for oxidative reaction because of high oxygen tension and the presence of hemoglobin and plasma membrane rich in polyunsaturated fatty acids (PUFA). The decrease in the GSH level in RBC may be related to decrease activity of GPx because this enzyme uses for its activity reduced glutathione $(\mathrm{GSH})$ as substrate $[14,15]$. The auto oxidation of glucose results in the formation of hydrogen 


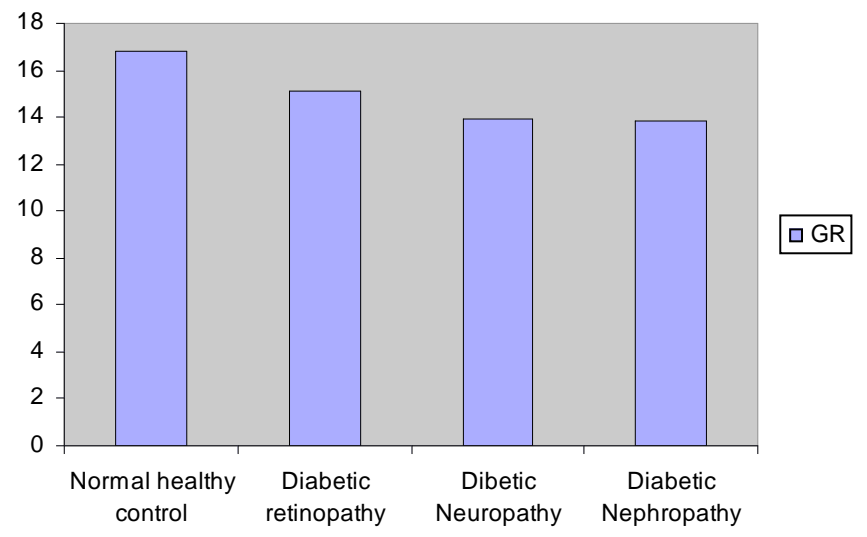

Fig. (4). Comparision of Glutathione Reductase in cases and control group.

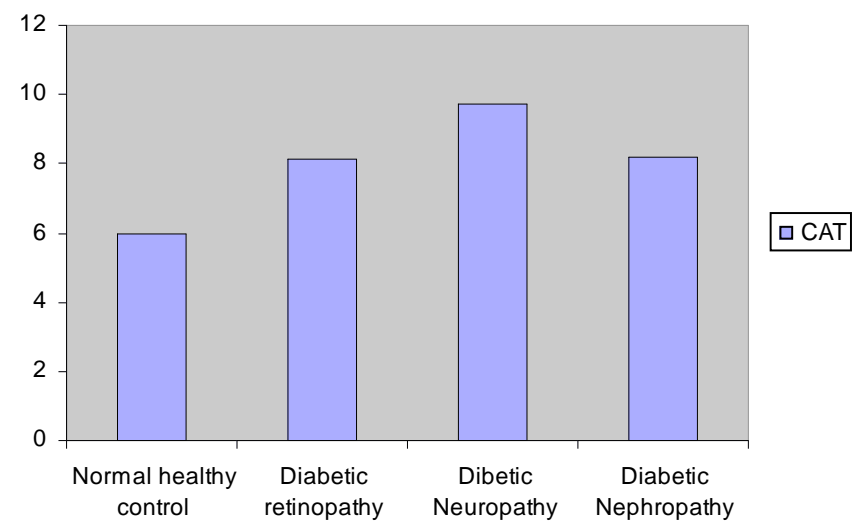

Fig. (5). Comparision of Catalase in cases and control group.

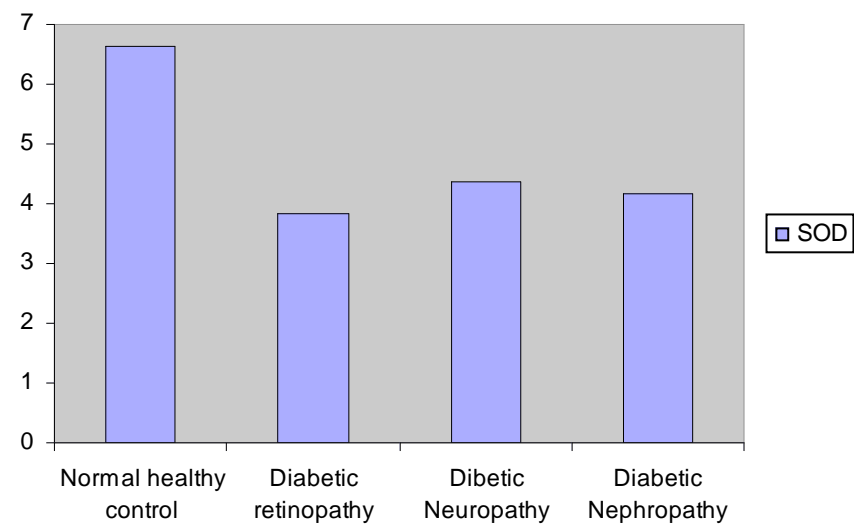

Fig. (6). Comparision of Superoxide dismutase in cases and control group.

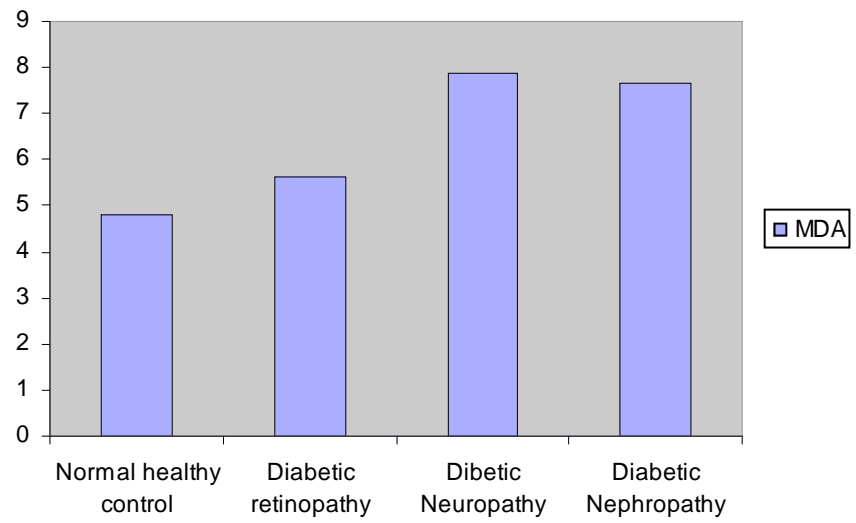

Fig. (7). Comparision of Malondialdehyde in cases and control group.

peroxide $\left(\mathrm{H}_{2} \mathrm{O}_{2}\right)$, which inactivate SOD [16]. The activity of SOD decreases in erythrocytes also due to ageing in diabetic subjects this could be due to increase in the glycation of SOD [17]. The level of glutathione reductase (GR) in erythrocytes was significantly decreased $(\mathrm{P}<0.001)$. This decrease may be due to glycation of enzyme [18] and reduction in NADPH, which is used by GR as a source of reducing power. This decrease may also be due to decreased level of GPx in the erythrocyte [19]. The increase in the activity of catalase in adult diabetics as compared to the control group is consistent with the observation of Ceballos et al. [20] who explained that during ageing process the steady state concentration of $\mathrm{H}_{2} \mathrm{O}_{2}$ may be much higher which could enhance peroxidation of PUFA in cell membrane, this lead to the lysis of erythrocytes resulting in the increase in the level of antioxidant enzymes (GPx \& Catalase) in the extracellular fluid. In erythrocytes, $\mathrm{H}_{2} \mathrm{O}_{2}$ is mainly detoxified by GPx and GR. When the activity of GPx decreases due to nonavailability of NADPH and reduced glutathione (GSH), the second enzyme catalases rises and disposes off the $\mathrm{H}_{2} \mathrm{O}_{2}$. Kumar et al. [21] reported that due to decreased activity of GPx, there is compensatory increase in the catalase activity. Inal et al. [22] also reported increased activity of CAT with age due to increase formation of $\mathrm{H}_{2} \mathrm{O}_{2}$.

Further the study shows the increase in the MDA level due to decreased activity of most of the antioxidant enzyme as reported by Ohtsuki T et al. [23]. The increase in the level of the MDA may be correlated with hyperglycemia in these patients because of autooxidation of glucose, which causes the generation of free radicals. The persistent, increase in blood glucose in diabetes mellitus results in the generation of high levels of reactive oxygen species (ROS)/MDA. The

Table 1. The Status of Fasting Blood Sugar (FBS), Antioxidant Enzymes (AOEs) and Malondialdehyde (MDA) in Microvascular Complications of Diabetes Mellitus

\begin{tabular}{|l|c|c|c|c|c|c|c|}
\hline \multicolumn{1}{|c|}{ Subjects } & $\begin{array}{c}\text { FBS Mmol/l } \\
\text { Mean } \pm \text { S.D }\end{array}$ & $\begin{array}{c}\text { GSH Mg\% } \\
\text { Mean } \pm \text { S.D }\end{array}$ & $\begin{array}{c}\text { GPx U/gmHb } \\
\text { Mean } \pm \text { S.D }\end{array}$ & $\begin{array}{c}\text { GR U/gmP } \\
\text { Mean } \pm \text { S.D }\end{array}$ & $\begin{array}{c}\text { CAT U/gmP/ml } \\
\text { Mean } \pm \text { S.D }\end{array}$ & $\begin{array}{c}\text { SOD UmgP/ml } \\
\text { Mean } \pm \text { S.D }\end{array}$ & $\begin{array}{c}\text { MDA nmol/ml } \\
\text { Mean } \pm \text { S.D }\end{array}$ \\
\hline \hline Normal Healthy Control & $5.05 \pm 0.48$ & $14.53 \pm 2.30$ & $8.82 \pm 1.16$ & $16.84 \pm 0.56$ & $6.00 \pm 0.66$ & $6.65 \pm 1.18$ & $4.79 \pm 0.72$ \\
Diabetic Retinopathy & $9.97 \pm 1.34$ & $10.14 \pm 1.27$ & $8.36 \pm 1.18$ & $15.09 \pm 0.81$ & $8.16 \pm 1.90$ & $3.85 \pm 1.07$ & $5.64 \pm 0.42$ \\
Diabetic Neuropathy & $10.10 \pm 1.61$ & $11.41 \pm 1.83$ & $15.44 \pm 2.65$ & $13.93 \pm 1.32$ & $9.74 \pm 0.92$ & $4.37 \pm 1.23$ & $7.86 \pm 1.50$ \\
Diabetic Nephropathy & $8.78 \pm 2.15$ & $10.76 \pm 1.69$ & $4.06 \pm 1.41$ & $13.85 \pm 1.13$ & $8.19 \pm 1.69$ & $4.15 \pm 1.13$ & $7.66 \pm 1.88$ \\
F. Value & 119.733 & 57.88 & 374.774 & 96.742 & 61.025 & 61.525 & 70.023 \\
\hline
\end{tabular}

Highly Significant $(\mathrm{p}<0.001)$. 
same finding is present in our study.

Therefore micro vascular complications of diabetes may be the result of this elevated level of oxidative stress (increase in the level of MDA) and the reduction in antioxidant defenses (GSH, GPx, GR and SOD).

\section{CONCLUSION}

The decreased antioxidant enzyme activities in Type 2 diabetic subjects might contribute to the development of micro vascular complications. By measuring the MDA level and by supplementing the antioxidants accordingly the physician could manage the severity of micro vascular complications of diabetic subjects

\section{REFERENCES}

[1] Taylor SI. Diabetes mellitus. In: Scriver CR, Beudelt AL, Sly W, Vally D, Eds. The metabolic basis of inherited disease, New York, MC Graw Hills 1995; p. 1841.

[2] Sinclair AJ, Barnett AH, Lunec J. Free radicals and antioxidant systems in health and disease. Br J Hosp Med 1990; 43: 334-44.

[3] Brownlee M, Cerami A, Viassara H. Advanced glycosylation end produts in tissue and the biochemical basis of diabetic complications. N Engl J Med 1998; 318: 1315-21.

[4] Nagasaka Y, Fujii S, Kaveko T. Effects of high glucose and sorbitol pathway on lipid peroxidation of erythrocytes. Horm Metab Res 1989; 21: 275-6.

[5] Trinder P. Estimation of blood glucose. Ann Clin Biochem 1969; 6: 24.

[6] Beutler E, Duron O, Kelly BM. Improved method for the determination of blood glutathione. J Lab Clin Med 1963; 61: 882-8.

[7] Hafeman DG, Sunde RA, Hoekstra WG. Effect of dietary selenium on erythrocyte and liver glutathione peroxidase in the rat. J Nutr 1974; 104: pp. 580-7.

[8] Horn HD. Glutathione Reductase. In: Bergmayer HU, Ed. Method in enzymatic analysis. Academic press, New York 1963; pp. 875-9.

[9] Sinha KA. Colorimetric assay of catalase. Anal Biochem 1972; 47: 389-94.
[10] Mishra HP, Fridovich I. The role of superoxide anion in the autooxidation of epinehrine and simple assay for superoxide dismutase. J Biol Chem 1972; 247: 3170-5.

[11] Jean CD, Maryse T, Marie JF. Plasma malondialdehyde levels during myocardial infarction. Clin Chim Acta 1983; 129: 319-22.

[12] West I. Radicals and oxidative stress in diabetes. Diabet Med 2000; 17: 171-80.

[13] Halliwell B. Free radicals, antioxidants and human disease: curiosity, cause or consequence? Lancet 1994; 344: 721-4.

[14] Jos J, Rybak M, Patin PH, Robert JJ, Boitard C, Thevenin R. Etudedes enzymes antioxidants dans le diabete insulino- independent de I enfant etde I adolescent. Diabete Metab 1990; 16: 493-503.

[15] Domingues C, Ruiz E, Gussinye M, Carrascosa A. oxidative stress at onset and in early stages of type I diabetes in children and adolescents. Diabetes Care 1998; 21: 1736-42.

[16] Fajans S. Diabetes mellitus, definition, classification, tests. Endocrinology Degroat L, $3^{\text {rd }}$ ed, Saunders Co, USA 1995; pp. 1411-22.

[17] Arai K, Maguchi S, Fujii S, Ishibashi H, Oikawa K, Taniguchi N. Glycation inactivation of human $\mathrm{Cu}-\mathrm{Zn}$ superoxide dismutase. J Biol Chem 1987; 262: 16969-72.

[18] Blakytny R, Harding JJ. Glycation (non-enzymatic glycosylation) inactivates glutathione reductase. Biochem J 1992; 288: 303-7.

[19] Sukalska KA, Pinto KA, Berntson JL. Decreased susceptibility of liver mitochondria from diabetic rats to oxidative damage and associated increase in alpha tochopherol. Free Radic Biol Med 1993; 14: 57-65.

[20] Ceballos I, Delebar JM, Nicole A. Expression of transfected human $\mathrm{Cu}-\mathrm{Zn}$ SOD in mouse L cells and NS20Y neuroblastoma cells induces enhancement of glutathione peroxidase activity. Biochem Biophys Acta 1998; 949: 58-64.

[21] Kumar PA, Rajagopal G. Lipid peroxidation in erythrocytes of patients with Type 2 diabetes mellitus. Indian $\mathrm{J}$ Clin Biochem 2003; 18: 71-4.

[22] Inal ME, Kanbak G, Sunal E. Antioxidant enzyme activities and malondialdehyde levels related to aging. Clin Chim Acta 2001; 305: 75-80.

[23] Ohtsuki T, Malasumoto M, Suzuki K, Taniguchi N, Kadanada T. Mitochondrial lipid peroxidation \& superoxide dismutase in rat hypertensive target organs. Am J Physiol 1995; 268: 1418-21. 